\title{
Supramolecular protein glue to boost enzyme activity
}

\author{
Yuna Shang ${ }^{1}$, Yue Liao ${ }^{2}$, Zhongju Ye ${ }^{3}$, Zhongyan Wang $^{1}$, Lehui Xiao ${ }^{3}$, Jie Gao ${ }^{1^{*}}$, Qigang Wang ${ }^{2^{*}}$ and \\ Zhimou Yang ${ }^{1 *}$
}

\begin{abstract}
Proteins possess many biological functions. However, they can easily degrade or aggregate, thus losing their bioactivity. Therefore, it is very important to develop materials capable of interacting with proteins and forming nanostructures for protein storage and delivery. In this study, we serendipitously found a novel peptide-based supramolecular protein glue (Nap-GFFYK $(\gamma \mathrm{E})_{2}-\mathrm{NH}_{2}$, compound 1) that could co-assemble with proteins into nanofibers and hydrogels. We found that compound 1 rapidly folded into a $\beta$-sheet conformation upon contact with many proteins but not with polymers. Total internal reflection fluorescence microscopy (TIRFM) images clearly show the formation of co-assembled nanofibers by proteins and the peptide. The supramolecular protein glue could improve the dispersion of enzymes (lipase and lysozyme) and therefore enhance their catalytic activity, especially at high temperatures. More importantly, the supramolecular protein glue could co-assemble with two enzymes, glucose oxidase/horseradish peroxidase (GOx/HRP) and GOx/cytochrome c (cyt c), to form nanofibers that significantly enhanced the catalytic activity of tandem enzymatic reactions. We envisioned the great potential of our supramolecular protein glue for protein storage, delivery, and bioactivity manipulation.
\end{abstract}

Keywords: protein glue, coassemble, $\beta$-sheet, enzyme activity

\section{INTRODUCTION}

Proteins are functional biomacromolecules that have many applications in fields ranging from biomedicine and materials science to industry. For instance, antibodies and growth factors are widely used as therapeutics in the clinic. Protein enzymes have also been widely used in industry to produce useful materials. However, proteins easily degrade or aggregate, thus losing their functions. In addition, many proteins form homogeneous or hetero- geneous complexes in nature where the proteins are localized within close proximity and function synergistically and complementarily [1,2]. Therefore, nanomaterials capable of interacting with proteins have attracted increasing research interest because they can retain and control the function of proteins [3-6], controllably deliver therapeutic proteins [7-16], and serve as artificial protein complexes to improve the biological or catalytic function of proteins [17-20]. For example, nanogels with encapsulated proteins/enzymes have been demonstrated to be useful for protein delivery and to boost the catalytic activity of tandem enzymatic reactions [21-24]. The strategy of protein engineering has also been developed and applied to construct protein complexes to improve their functions [25-30]. Though these strategies are promising, they need elegant designs or complicated syntheses. It would be advantageous to develop molecules capable of specifically interacting with proteins to form co-assembled nanostructures [31-35]. In this study, we reported a novel type of supramolecular protein glue that can specifically interact with proteins and form co-assembled nanofibers. We also demonstrated that the stability of proteins could be enhanced, and more importantly, the tandem enzymatic activity could be enhanced by the supramolecular protein glue.

\section{EXPERIMENTAL SECTION}

\section{Chemicals and materials}

Rink Amide Resin $\left(0.9 \mathrm{mmol} \mathrm{g}^{-1}\right)$ was bought from Nankai University resin Co. Ltd. Fmoc-Glu-OtBu, BocGlu-OtBu, Fmoc-Lys(Mtt)-OH, other Fmoc-amino acids and $o$-benzotriazol-1-yl- $N, N, N^{\prime}, N^{\prime}$-tetramethyluronium hexafluorophosphate (HBTU) were obtained from GL Biochem (Shanghai, China). All proteins were bought

\footnotetext{
${ }^{1}$ Key Laboratory of Bioactive Materials, Ministry of Education, State Key Laboratory of Medicinal Chemical Biology, College of Life Sciences, and Collaborative Innovation Center of Chemical Science and Engineering (Tianjin), Nankai University, Tianjin 300071, China

${ }^{2}$ School of Chemical Science and Engineering, Tongji University, Shanghai 200092, China

${ }^{3}$ State Key Laboratory of Medicinal Chemical Biology, College of Chemistry, Nankai University, Tianjin 300071, China

* Corresponding authors (emails: yangzm@nankai.edu.cn (Yang Z); wangqg66@tongji.edu.cn (Wang Q); chemgaojie@nankai.edu.cn (Gao J))
} 
from Solarbio (Beijing, China). Commercially available reagents and solvents were used without further purification, unless noted otherwise.

\section{Peptide synthesis}

The peptide derivative was prepared by solid phase peptide synthesis (SPPS) using Rink Amide Resin and the corresponding $\mathrm{N}$-Fmoc protected amino acids with side chains properly protected by a tertbutyl group $(t \mathrm{Bu})$ or 4 methyl-triphenyl (Mtt). Piperidine $(20 \%)$ in anhydrous $N, N^{\prime}$-dimethylformamide (DMF) was used during the deprotection of the Fmoc group. 1\% trifluoroacetic acid (TFA) in dichloromethane (DCM) was used during the deprotection of the Mtt group. After the last coupling step, excessive reagents were removed by a single DMF wash for $5 \mathrm{~min}$ ( $5 \mathrm{~mL}$ per gram of resin), followed by five steps of washing using DCM for $2 \mathrm{~min}$ ( $5 \mathrm{~mL}$ per gram of resin). Then $1 \%$ TFA was used for the deprotection of the Mtt group for 5 times every $5 \mathrm{~min}$ ( $5 \mathrm{~mL}$ per gram of resin). After deprotection of the Mtt group, the resin was washed with DCM and DMF 5 times each. The coupling reagent $o$-benzotriazol-1-yl- $N, N, N^{\prime}, N^{\prime}$-tetramethyluroniumhexafluorophosphate (HBTU) and amino acid Fmoc-Glu-OH were added to the solid phase synthesis tube. After reacting for $2 \mathrm{~h}$, the Fmoc protecting group was removed, and another Boc-Glu-OH was added to the tube for next amino acid ligation. Finally, the peptide derivative was cleaved using 95\% TFA containing $2.5 \%$ trimethylsilane (TMS) and $2.5 \% \mathrm{H}_{2} \mathrm{O}$. The detailed synthetic route and characterizations of the products are shown in Scheme S1 and Figs S1-S9 of Supplementary information.

\section{Hydrogel formation}

Compound 1 (2.5 mg) was dispersed in phosphate buffer saline (PBS, pH 7.4) at a final concentration of $0.5 \mathrm{wt} \%$ using sodium carbonate to adjust the final $\mathrm{pH}$ to 7.4. Each protein was dispersed in PBS buffer solution ( $\mathrm{pH} 7.4$ ) at a final concentration of $10 \mu \mathrm{g} \mu \mathrm{L}^{-1}$. The protein was then dispersed evenly in the hydrogel by vortex. The final concentration of the protein in the hydrogel was $500 \mu \mathrm{g} \mathrm{mL}^{-1}$. The mixture was maintained at $37^{\circ} \mathrm{C}$ for half an hour, and then the hydrogelation process was observed.

\section{Preparation of rhodamine B-labelled lipase}

Lipase $\left(5 \mathrm{mg} \mathrm{mL}^{-1}\right)$ and 1 equiv. of rhodamine B 5-isothiocyanate were mixed in a dialysis bag and placed at $4^{\circ} \mathrm{C}$ for stirring overnight. The rhodamine B-labelled lipase was obtained after dialysis and freeze-dry.

\section{Protein colocalization}

To verify the co-assembly between peptide and protein, the related fluorescence colocalization imaging experiment was performed on a home-built total internal reflection fluorescence microscope (TIRFM) imaging system based on a Nikon Ti-U inverted epi-fluorescence microscope (Japan). A semiconductor laser (532 and $473 \mathrm{~nm}$ ) was mounted on the back of the microscopy to excite the dye, as rhodamine $\left(\lambda_{\text {exc. }}=554 \mathrm{~nm}\right)$ was used to label the protein and $(E)-4-(2-(9-(2-(2-m e t h o x y e t h o x y)$ ethyl)-9H-carbazol-3-yl)vinyl)-1-methylquinolinium iodide (SLM) $\left(\lambda_{\text {exc. }}=488 \mathrm{~nm}\right)$ was used to label the preformed fibrils. The fluorescence from the dye was collected by a 100xTIRF objective (NA 1.49) and then recorded with an Andor iXon 897 EMCCD. The pixel size of the CCD camera was $16 \mu \mathrm{m} \times 16 \mu \mathrm{m}$.

For the fluorescence imaging, the preformed fibrils were immobilized on a standard glass coverslip functionalized with amino groups. The un-fixed fibrils and other molecules were washed away with deionized (DI) water three times. Fluorescence from the rhodamine labelled protein was captured first. Then, fresh SLM solution which can effectively adsorb onto the fibrils was injected into the channel and imaged on the same condition in situ. All images were analyzed by the public image processing software Image J (http://rsbweb.nih.gov/ij/).

\section{Transmission electron microscopy}

The hydrogel $(5 \mu \mathrm{L})$ was added to the carbon-coated copper grids, and the excess samples were removed with filter paper. The sample was washed with ultra-pure water two or three times. After the excess water was removed, the grid was placed in the desiccator until it was completely dried. The sample was observed with transmission electron microscopy (TEM).

\section{Circular dichroism (CD) spectrum}

The hydrogel was added to the $0.1 \mathrm{~cm}$ quartz spectrophotometer cell $(20-\mathrm{C} / \mathrm{Q} / 0.1)$ for $\mathrm{CD}$ spectrum test. The wavelength was set from 185 to $280 \mathrm{~nm}$, and the acquisition period was $0.5 \mathrm{~s}$ and the step length was $0.5 \mathrm{~nm}$. A BioLogic (mos-450) system was used to record the CD spectra. The final spectrum was subtracted from the PBS background.

\section{Rheology}

We dispersed compound $\mathbf{1}$ in PBS at a concentration of $0.5 \mathrm{wt} \%$, and then added 10,30 , and $50 \mathrm{wt} \%$ of lipase to the solution. The resulting solutions were immediately added between $40 \mathrm{~mm}$ parallel plates for rheology test. 
The mode of dynamic frequency sweep was performed in the region of $0.1-100 \mathrm{rad} \mathrm{s}^{-1}$ at the strain of $1 \%$ at $37^{\circ} \mathrm{C}$. The mode of time sweep was tested at the strain of $1 \%$ and frequency of $1 \%$ at $37^{\circ} \mathrm{C}$.

\section{Zeta-potential and average diameter}

The Zeta-potential and average diameter of the compounds in PBS buffer solution was determined by dynamic light scattering (DLS). Solutions containing different proteins were tested and the light scattering intensity was recorded.

\section{Microscale thermophoresis}

Proteins were labeled with the fluorescent dye NT-647 using Monolith $\mathrm{NT}^{\mathrm{TM}}$ Protein Labelling Kits (cysteine-reactive) (NanoTemper Technologies, Germany). PBS buffer containing $0.05 \%$ Tween $20(\mathrm{pH} \mathrm{7.4)}$ was used as the assay buffer. For the interaction experiments of fluorescent-proteins with compound $\mathbf{1}$ or $\mathbf{2}$, the concentrations of the labeled proteins were maintained constant, while the concentrations of compound $\mathbf{1}$ or $\mathbf{2}$ varied from $0.25 \mu \mathrm{mol} \mathrm{L}^{-1}$ to $10 \mathrm{mmol} \mathrm{L}^{-1}$. Then the solution of fluorescent-proteins was mixed with solutions containing different concentrations of compound $\mathbf{1}$ or $\mathbf{2}$ at 1:1 volume ratio. After a short incubation time, the samples were loaded into MST NT.115 standard glass capillaries and the analysis was performed using the Monolith NT.115 system (NanoTemper Technologies, Germany). The dissociation kinetics $\left(K_{\mathrm{D}}\right)$ value was calculated using the NanoTemper software package.

\section{Measurement of catalytic activity}

The test of the enzyme catalytic activity was conducted by monitoring the absorbance at $420 \mathrm{~nm}$ using a UV-vis spectrophotometer (SHIMADZU UV-2700). Aqueous solution containing glucose $\left(1 \mathrm{mmol} \mathrm{L}^{-1}\right)$ and 2,2'-azinobis(3-ethylbenzothiazoline-6-sulfonic acid) $\left(\mathrm{ABTS}^{2-}\right)$ mmol L ${ }^{-1}$ ) was chosen as sufficient substrates for the measurement of the catalytic activity of glucose oxidase/ horseradish peroxidase (GOx/HRP) cascade enzymes. Briefly, $1 \mu \mathrm{L}$ of GOx $\left(2 \mathrm{mg} \mathrm{mL}^{-1}\right)$ in PBS and $1 \mu \mathrm{L}$ of HRP $\left(2 \mathrm{mg} \mathrm{mL}^{-1}\right)$ mixed in PBS as free enzymes, (or equal amounts of GOx and HRP within $1.0 \mathrm{wt} \%$ of compound 1 as immobilized enzymes by hydrogel) were added to $3 \mathrm{~mL}$ of the mentioned substrate solution. The absorbance at $420 \mathrm{~nm}$ of the initial stage of reaction was recorded with an interval of $12 \mathrm{~s}$ in $1 \mathrm{~min}$. The product concentration of $\mathrm{ABTS}^{-}$at its oxidation state, with the molar extinction coefficient was $3.6 \times 10^{4} \mathrm{~L} \mathrm{~mol}^{-1} \mathrm{~cm}^{-1}$, could be calculated according to Beer-Lambert's Law.
Then the initial reaction rate representing enzyme catalytic activity was calculated as the slope value of the linear fitting of concentration-time curve. The catalytic activity of $\mathrm{GOx} /$ cytochrome $\mathrm{c}$ (cyt c) cascade system was measured by the same method.

The activity of lysozyme was measured using spectrophotometric turbidity assay on a SHIMADZU UV-vis 2700 spectrophotometer at room temperature. The substrate solution of Micrococcus lysodeikticus was prepared with a concentration of $3 \mathrm{mg} \mathrm{mL}^{-1}$. Lysozyme $\left(1 \mathrm{mg} \mathrm{mL}^{-1}\right.$, $10 \mu \mathrm{L}$ ) in PBS (or 1.0 wt\% compound 1 with equal amounts of lysozyme) was mixed with $1 \mathrm{~mL}$ of the substrate solution immediately, and the change in absorbance at $450 \mathrm{~nm}$ was detected with a 0.2 min-interval in $1 \mathrm{~min}$. The decline degree of turbidity representing enzyme activity could be calculated by the $\Delta \mathrm{OD} 450$-time curve.

The enzyme catalytic property of lipase from porcine pancreas was determined with the substrate of 4-nitrophenyl palmitate ( $\mathrm{pNP}$ ) on a microplate reader (BioTek ELX800) at $405 \mathrm{~nm}$. Firstly, $15 \mathrm{mg}$ pNP dissolved in $5 \mathrm{~mL}$ isopropanol and $45 \mathrm{~mL}$ phosphate buffer $(\mathrm{pH} 7.2)$ was used as the substrate solution. Lipase $\left(1 \mathrm{mg} \mathrm{mL}^{-1}\right.$, $100 \mu \mathrm{L}$ ) in PBS (or 1.0 wt\% compound 1 with equal amounts of lipase) was mixed with $500 \mu \mathrm{L}$ of the asprepared pNP solution and $40 \mu \mathrm{L} \mathrm{CaCl}_{2}\left(100 \mathrm{mmol} \mathrm{L}^{-1}\right)$ aqueous solution, and subsequently incubated for an appropriate period such as $12,24,36,48$ and $60 \mathrm{~min}$. After being centrifugated, the absorbance of $100 \mu \mathrm{L}$ of the upper colourful solution was detected at $405 \mathrm{~nm}$. At least three samples were used for each test.

\section{RESULTS AND DISCUSSION}

We serendipitously found the supramolecular protein glue. First, we planned to synthesize peptide derivatives responsive to a cancer cell overexpressed enzyme $\gamma$-glutamyltransferase (GGT) [36,37] by enzyme-instructed self-assembly (EISA) [38-40]. We attached two $\gamma$-glutamic acids $(\gamma$ Es) to the side chain of lysine $(\mathrm{K})$ in a selfassembling peptide derivative, Nap-GFFYK-NH$H_{2}$. The resulting molecule, Nap-GFFYK $(\gamma \mathrm{E})_{2}-\mathrm{NH}_{2}$ (Fig. 1a, compound 1), was expected to dissolve well in aqueous solutions and to be converted to the self-assembling NapGFFYK-NH $\mathrm{N}_{2}$ by GGT. We obtained Nap-GFFYK $(\gamma \mathrm{E})_{2}-$ $\mathrm{NH}_{2}$ by standard solid phase peptide synthesis, which dissolved well in PBS and formed a clear solution at a concentration of $0.5 \mathrm{wt} \%$ (Fig. 1b). Unexpectedly, the addition of GGT $\left(13.8 \mathrm{U} \mathrm{mL}^{-1}\right)$ immediately changed the clear solution to a transparent hydrogel (Fig. 1b). However, the liquid chromatography-mass spectrometry (LC- 

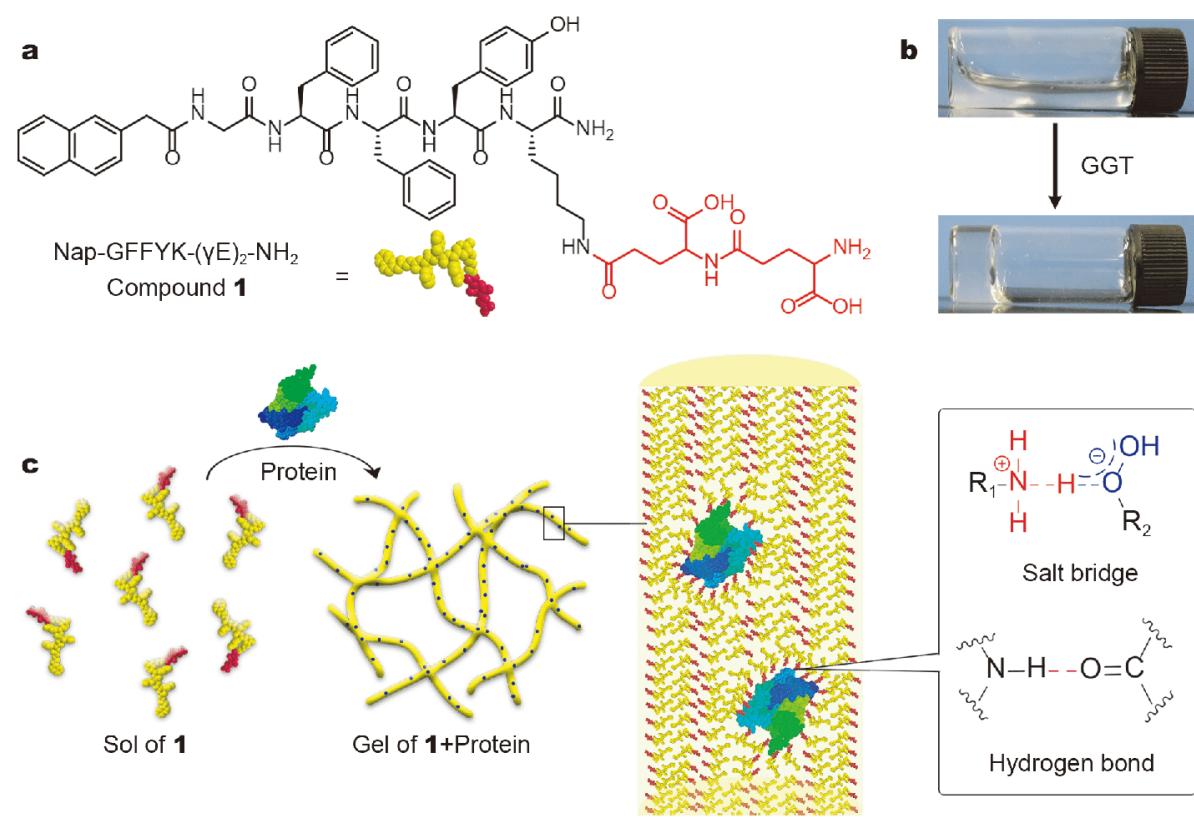

Figure 1 (a) The chemical structure of $\mathbf{1}$. (b) Optical images of a solution of $\mathbf{1}(0.5 \mathrm{wt} \%)$ and the corresponding gel formed by adding GGT (13.8 $\mathrm{U} \mathrm{mL}^{-1}$ ) immediately. (c) Schematic illustration for the formation of nanofibers of 1 and proteins.

MS) results indicated that compound 1 remained intact in the hydrogel. TEM images revealed anomalous short nanofibers with diameters of $7.6 \mathrm{~nm}$ and lengths less than $150 \mathrm{~nm}$ and entangled long nanofibers with diameters of $11.5 \mathrm{~nm}$ and lengths greater than $500 \mathrm{~nm}$ in the solution and the gel (Fig. S10), respectively. These observations clearly indicated that compound $\mathbf{1}$ interacted with the enzyme GGT and formed nanofibers for hydrogelation.

We speculated whether hydrogel formation of $\mathbf{1}$ was unique to the addition of GGT. We therefore added other proteins, including lysozyme, trypsin, acetylcholinesterase (ACE), proteinase $\mathrm{K}$, urease and lipase, to the solution of 1. We observed hydrogels formation for all of these proteins (Fig. S11). The addition of polymers, such as polyethylene glycol (PEG) and glucan, did not convert the solution of 1 to a hydrogel (Fig. S11), eliminating the possibility of concentration-induced self-assembly. To further explore the specific time of hydrogel formation after the addition of protein, we dispersed compound $\mathbf{1}$ in PBS at a concentration of $0.5 \mathrm{wt} \%$, and then added the $0.05 \mathrm{wt} \%$ lipase. The resulting solution was immediately tested by rheology with the mode of dynamic time sweep at the strain of $1 \%$ and frequency of $1 \%$ at $37^{\circ} \mathrm{C}$. The rheological result in Fig. S12 indicated that the hydrogel began to form about $17 \mathrm{~min}$ after the addition of the protein. We also synthesized Nap-GFFYK $(\gamma \mathrm{E})-\mathrm{NH}_{2}$ and Nap-GFFYK $(\gamma E)_{3}-\mathrm{NH}_{2}$ with one and three $\gamma$ Es at the side chain of $K$ as control compounds. The Nap-GFFYK $(\gamma E)$ -
$\mathrm{NH}_{2}$ itself did not form clear PBS solutions in the absence or presence of different kinds of proteins (Fig. S13). Nap$\operatorname{GFFYK}(\gamma \mathrm{E})_{3}-\mathrm{NH}_{2}$ did form a clear PBS solution at the concentration of $0.5 \mathrm{wt} \%$ (Fig. S14), but adding different kind of proteins to the solution did not convert it to a gel (final protein concentration is $0.05 \mathrm{wt} \%$, Fig. S14). These observations indicated the importance of amphiphilicity of the peptide for protein-induced hydrogelation and suggested that compound $\mathbf{1}$ served as a protein glue to form nanofibers for hydrogelation.

TEM images of the hydrogels show highly uniform nanofibers (Fig. 2a-f). However, the diameters of the nanofibers were different and approximately 9.9, 10.9, $11.2,11.4,11.5$, and $11.9 \mathrm{~nm}$ for gels formed by adding lysozyme, trypsin, ACE, proteinase $\mathrm{K}$, urease, and lipase to the solution of $\mathbf{1}$, respectively. These results suggested that the proteins were incorporated within the nanofibers that were formed by the co-assembly of $\mathbf{1}$ and the proteins. To demonstrate the co-assembly between $\mathbf{1}$ and proteins, we obtained TIRFM images of the nanofibers. We used rhodamine B-labelled lipase to form nanofibers and hydrogels with $\mathbf{1}$. The nanofibers in the hydrogel were stained with SLM. The TIRFM image in Fig. $2 \mathrm{i}$ shows that most of the lipase indeed co-localized with $\mathbf{1}$, clearly demonstrating that the protein and $\mathbf{1}$ co-assembled into nanofibers. To further investigate its ability to encapsulate proteins, we added 10, 30 and $50 \mathrm{wt} \%$ lipase to solution of $\mathbf{1}$ for hydrogelations and surprisingly 

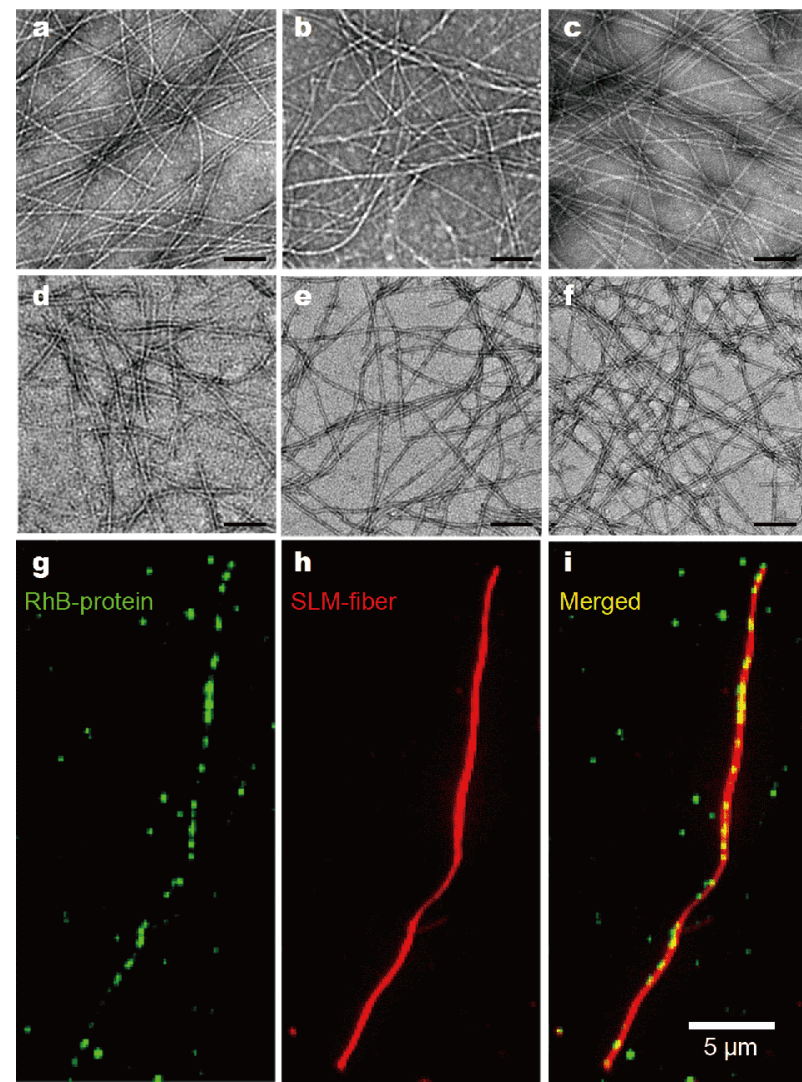

Figure 2 (a-f) TEM images of gels formed by adding lysozyme, trypsin, $\mathrm{ACE}$, proteinase $\mathrm{K}$, urease, and lipase (final concentration: $0.05 \mathrm{wt} \%$ ), respectively, to solution of $\mathbf{1}$ (final concentration: $0.5 \mathrm{wt} \%$ ) (scale bar: $100 \mathrm{~nm}$ ). (g-i) TIRFM images of the nanofibers in the gel containing $0.5 \mathrm{wt} \%$ of 1 and $0.05 \mathrm{wt} \%$ of lipase.

found that the mechanical strength of the resulting hydrogels decreased with increasing protein amount (Fig. S15). Once the amount of protein exceeded the maximum load, it would not form a gel but still be a solution. The maximum amount of protein that could be used for hydrogelations with 1 was 170, 150, 50, 30, 20 and $10 \mathrm{wt} \%$ for trypsin, proteinase $\mathrm{K}$, lipase, lysozyme, urease and ACE, respectively (Fig. S16). We speculated that the different maximum amounts of the encapsulated protein were due to the different properties of the proteins, including surface charge, size, and hydrophobic domain, which needs to be investigated in a future study.

To understand the mechanism of hydrogel formation, we collected CD spectra of solution of $\mathbf{1}$, solutions of proteins and the resulting hydrogels. The $\mathrm{CD}$ spectrum of solution of $1(0.5 \mathrm{wt} \%)$ showed no significant signals in neither the positive nor negative area (Fig. S17), indicating that the peptide itself did not adopt an ordered secondary structure in the solution. At the low con- centration $(0.05 \mathrm{wt} \%)$, all the protein solutions exhibited very weak CD signals (Fig. S18). However, compound 1 rapidly folded into a $\beta$-sheet structure upon mixing with the protein, as indicated by a positive peak at approximately $190 \mathrm{~nm}$ and a negative peak at approximately $215 \mathrm{~nm}$ (Fig. 3a). The CD spectra for the gel of 1 and lipase at different time points indicated that $\mathbf{1}$ folded into a stable $\beta$-sheet conformation within $75 \mathrm{~min}$ (Fig. 3b). We also analyzed the time required for the formation of a stable $\beta$-sheet conformation by adding different amounts of lipase. We found that the time was shorter as the lipase content increased (Fig. S19). These observations clearly indicated that the protein induced folding of $\mathbf{1}$, thus leading to the formation of co-assembled nanofibers. We synthesized Nap-GFFYK(E) $)_{2}-\mathrm{NH}_{2}$ (compound 2) as another control molecule of $\mathbf{1}$. Both compounds $\mathbf{1}$ and $\mathbf{2}$ had identical molecular weights, similar surface charges and average diameter (Figs S20, S21). However, adding different kinds of proteins to the solution of $\mathbf{2}$ did not lead to hydrogel formation, but rather clear solutions (Fig. S22). We detected the CD of solution containing $0.5 \mathrm{wt} \%$ of 2 and $0.05 \mathrm{wt} \%$ of lipase and found no significant change in the secondary structure (Fig. S23). We realized that $\mathbf{1}$ possessed an $\alpha$-amino acid at the side chain of the peptide, which might form salt bridges and hydrogen bonds with proteins. Then, we used MST to determine the binding affinity $\left(K_{\mathrm{D}}\right)$ of compounds $\mathbf{1}$ and $\mathbf{2}$ with various proteins. The $K_{\mathrm{D}}$ value of $\mathbf{1}$ with lysozyme, trypsin, $\mathrm{ACE}$, proteinase $\mathrm{K}$, urease, and lipase was calculated to be $377.5,263.1,173.1,156.7,146.8$ and $135.9 \mu \mathrm{mol} \mathrm{L}^{-1}$, respectively (Fig. 3d). However, there was no measurable binding affinity between 2 and all the proteins (Fig. S24). These observations highlighted the importance of the spatial configuration of the $\mathrm{NH}^{3+}$ and $\mathrm{COO}^{-}$groups in the interaction between the peptide and the protein and clearly showed that the specific binding between $\mathbf{1}$ and proteins played an important role in the hydrogelations.

After demonstrating that compound 1 could bind proteins and co-assemble with them to form nanofibers, we speculated whether it could benefit the catalytic ability of the laden enzyme, which was a type of bioactive protein. For the liposoluble enzymes, such as lysozyme and lipase, their catalytic efficiencies in the nanofiber are shown in Fig. 4a, b. The gel-bound lysozyme and lipase exhibited higher hydrolytic ability compared with the free enzyme, which was 1.19 and 1.78 times in average, respectively. The better dispersion of liposoluble enzymes within amphiphilic nanofibers was the main reason for the enhanced activity of the gel-bound hydrolases (Fig. S25). The immobilization in nanofibers could also 

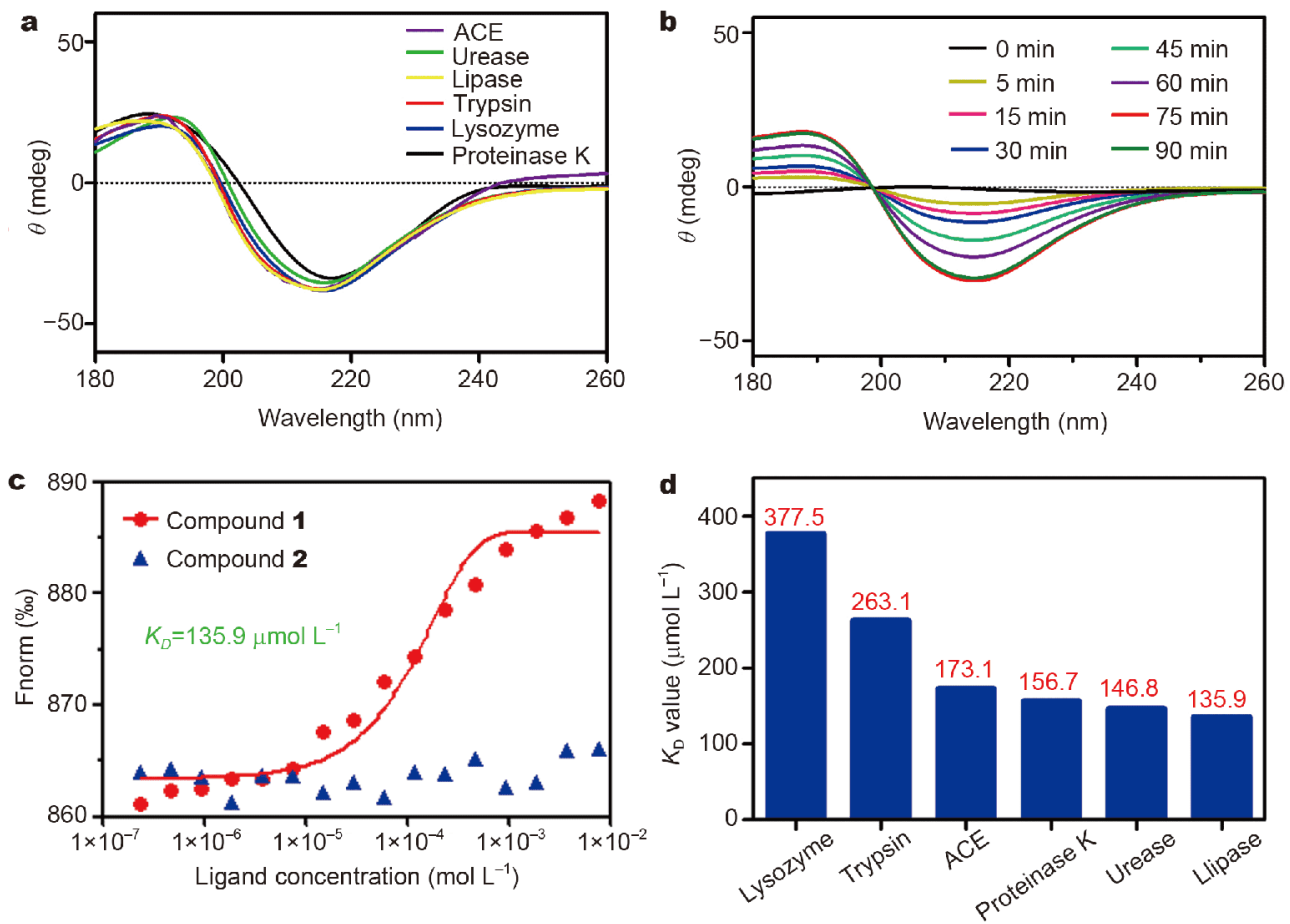

Figure 3 (a) CD spectra of hydrogels containing $0.5 \mathrm{wt} \%$ of $\mathbf{1}$ and $0.05 \mathrm{wt} \%$ of different proteins. (b) CD spectra of the solution of 1 at different time points after adding lipase. (c) The fitting curve of microscale thermophoresis (MST) to calculate the $K_{\mathrm{D}}$ value between 1 or $\mathbf{2}$ and lipase. (d) The $K_{\mathrm{D}}$ value of $\mathbf{1}$ with different proteins.

retain almost all activity of the HRP enzyme, which is a typical water-soluble peroxidase with high biocatalytic efficiency (Fig. S26).

The superactivity of tandem oxidase and peroxidase within the supramolecular nanofibers was exceptional. The activities of GOx/HRP and GOx/cyt c were analyzed by a tandem chromogenic reaction of oxygen, glucose and ABTS $^{2-}$ (Figs S27, S28). As shown in Fig. 4c, the tandem enzymatic activity of GOx/HRP embedded in the nanofibers increased as compared with free GOx/HRP. The reaction rate of the former was 1.41 times greater than that of the latter. Additionally, GOx coupled with cyt $c$ by compound 1 showed much higher efficiencies than the two protein molecules freely dispersed in the water solution (Fig. 4d). The biocatalytic ability of the immobilized GOx/cyt c was 4.25 times greater than that of their free form. The existing microchannel along with the supramolecular nanofiber shortened the diffusive distance between the two co-assembled proteins, which was beneficial to the delivery of the intermediate product of $\mathrm{H}_{2} \mathrm{O}_{2}$ and thus greatly promoted their catalytic activity [41].

The nanofibers formation also rendered the loaded single and dual enzymes with better thermal stability compared with the free enzymes. The activity of immobilized lipase in nanofibers was compared with that of the free lipase after various temperature incubations. As shown in Fig. 4e, the yield of the colorful product produced by lipase in nanofibers was greater than that produced by the free enzyme under all conditions. The bound GOx/HRP in nanofibers also demonstrated a relatively higher efficiency than the free GOx/HRP at various catalytic temperatures (Fig. 4f). The enzymes immobilized in the nanofibers maintained a majority of catalytic ability by relieving the thermal shock even at $65^{\circ} \mathrm{C}$. Furthermore, the free GOx/HRP nearly completely lost their tandem catalytic ability at this temperature due to thermal inactivation. The nanofibers also retained the single and dual enzyme stability even after one month of storage, while the free enzyme lost most of its catalytic ability (Figs S29, S30).

\section{CONCLUSIONS}

In summary, we developed a novel molecule (compound 1) capable of specifically interacting with proteins and coassembling with them to form nanofibers and hydrogels. The side chain $\gamma \mathrm{E}$ was crucial for the formation of salt bridges and hydrogen bonds with proteins. Our supramolecular protein glue was very useful for single or dual enzyme immobilization to enhance their catalytic activity. In addition, we envisioned the great potential of this 

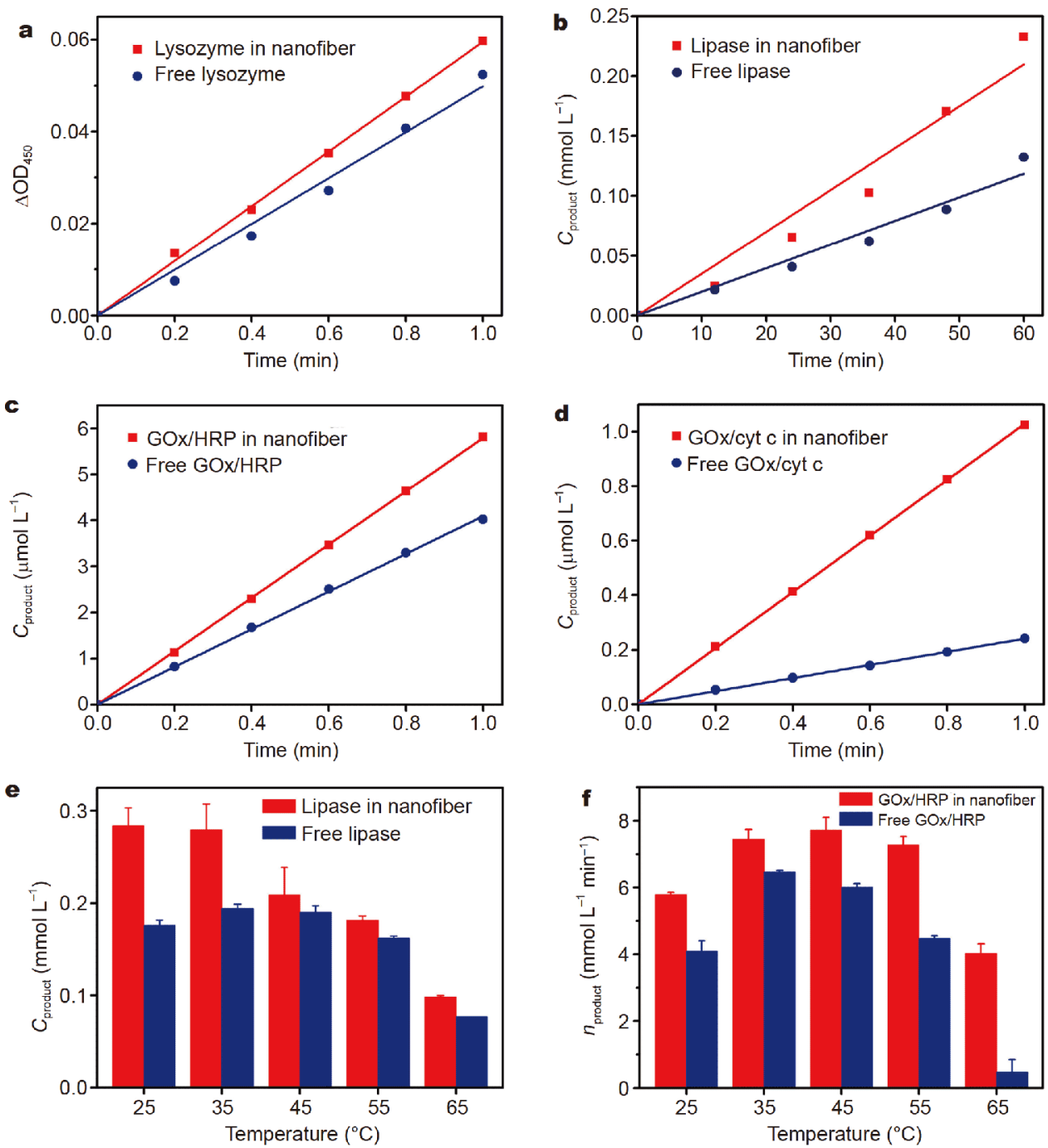

Figure 4 Biocatalytic reaction courses (solid scatters) of different enzyme systems encapsulated in nanofiber and in free form fitted to linear fitting curves (solid lines). Hydrogel contains $1 \mathrm{wt} \%$ of 1 and (a) $0.1 \mathrm{wt} \%$ of lysozyme, (b) $0.1 \mathrm{wt} \%$ of lipase, (c) $0.1 \mathrm{wt} \%$ of GOx and $0.1 \mathrm{wt} \%$ of HRP, (d) 0.1 wt\% of GOx and $0.1 \mathrm{wt} \%$ of cyt c. Free enzymes in PBS solutions are with the same content. (e-f) The biocatalytic activity of lipase and GOx/HRP cascade enzyme bounded in and without nanofiber at different temperatures.

supramolecular protein glue in protein/vaccine delivery, construction of multiple protein complexes, and the development of supramolecular therapeutics.

\section{Received 26 February 2019; accepted 26 March 2019; published online 17 April 2019}

1 Schrader M, Fahimi HD. Mammalian peroxisomes and reactive oxygen species. Histochem Cell Biol, 2004, 122: 383-393

2 Sheikh FG, Pahan K, Khan M, et al. Abnormality in catalase import into peroxisomes leads to severe neurological disorder. Proc Natl Acad Sci USA, 1998, 95: 2961-2966

3 Zorn JA, Wille H, Wolan DW, et al. Self-assembling small molecules form nanofibrils that bind procaspase- 3 to promote activation. J Am Chem Soc, 2011, 133: 19630-19633
4 Sangiambut S, Channon K, Thomson NM, et al. A robust route to enzymatically functional, hierarchically self-assembled peptide frameworks. Adv Mater, 2013, 25: 2661-2665

5 Wen JH, Vincent LG, Fuhrmann A, et al. Interplay of matrix stiffness and protein tethering in stem cell differentiation. Nat Mater, 2014, 13: 979-987

6 Wang Y, Bakota E, Chang BHJ, et al. Peptide nanofibers preconditioned with stem cell secretome are renoprotective. J Am Soc Nephrol, 2011, 22: 704-717

7 Lock LL, Li Y, Mao X, et al. One-component supramolecular filament hydrogels as theranostic label-free magnetic resonance imaging agents. ACS Nano, 2017, 11: 797-805

8 Cross ER, Sproules S, Schweins R, et al. Controlled tuning of the properties in optoelectronic self-sorted gels. J Am Chem Soc, 2018, 140: $8667-8670$

9 Wang Y, Lovrak M, Liu Q, et al. Hierarchically compartmentalized 
supramolecular gels through multilevel self-sorting. J Am Chem Soc, 2019, 141: 2847-2851

10 Shigemitsu H, Fujisaku T, Tanaka W, et al. An adaptive supramolecular hydrogel comprising self-sorting double nanofibre networks. Nat Nanotech, 2018, 13: 165-172

11 Luo Z, Wu Q, Yang C, et al. A powerful $\mathrm{CD}^{+}{ }^{+} \mathrm{T}$-cell stimulating $D$-tetra-peptide hydrogel as a very promising vaccine adjuvant. Adv Mater, 2017, 29: 1601776

12 Hudalla GA, Modica JA, Tian YF, et al. A self-adjuvanting supramolecular vaccine carrying a folded protein antigen. Adv Healthcare Mater, 2013, 2: 1114-1119

13 Hudalla GA, Sun T, Gasiorowski JZ, et al. Gradated assembly of multiple proteins into supramolecular nanomaterials. Nat Mater, 2014, 13: 829-836

14 Purcell BP, Lobb D, Charati MB, et al. Injectable and bioresponsive hydrogels for on-demand matrix metalloproteinase inhibition. Nat Mater, 2014, 13: 653-661

15 Zhang N, Zhao F, Zou Q, et al. Multitriggered tumor-responsive drug delivery vehicles based on protein and polypeptide coassembly for enhanced photodynamic tumor ablation. Small, 2016, 12: $5936-5943$

16 Brown N, Lei J, Zhan C, et al. Structural polymorphism in a selfassembled tri-aromatic peptide system. ACS Nano, 2018, 12: 32533262

17 Lee SS, Fyrner T, Chen F, et al. Sulfated glycopeptide nanostructures for multipotent protein activation. Nat Nanotech, 2017, 12: 821-829

18 Liu Y, Du J, Yan M, et al. Biomimetic enzyme nanocomplexes and their use as antidotes and preventive measures for alcohol intoxication. Nat Nanotech, 2013, 8: 187-192

19 Wilner OI, Weizmann Y, Gill R, et al. Enzyme cascades activated on topologically programmed DNA scaffolds. Nat Nanotech, 2009, 4: $249-254$

20 Makam P, Gazit E. Minimalistic peptide supramolecular co-assembly: expanding the conformational space for nanotechnology. Chem Soc Rev, 2018, 47: 3406-3420

$21 \mathrm{Wu} \mathrm{Q}, \mathrm{Su} \mathrm{T}, \mathrm{Mao} \mathrm{Y}$, et al. Thermal responsive microgels as recyclable carriers to immobilize active proteins with enhanced nonaqueous biocatalytic performance. Chem Commun, 2013, 49: $11299-11301$

22 Wei Q, Xu M, Liao C, et al. Printable hybrid hydrogel by dual enzymatic polymerization with superactivity. Chem Sci, 2016, 7: 2748-2752

23 Okesola BO, Mata A. Multicomponent self-assembly as a tool to harness new properties from peptides and proteins in material design. Chem Soc Rev, 2018, 47: 3721-3736

24 Gao Y, Zhao F, Wang Q, et al. Small peptide nanofibers as the matrices of molecular hydrogels for mimicking enzymes and enhancing the activity of enzymes. Chem Soc Rev, 2010, 39: 34253433

25 Dueber JE, Wu GC, Malmirchegini GR, et al. Synthetic protein scaffolds provide modular control over metabolic flux. Nat Biotechnol, 2009, 27: 753-759

26 Shanbhag BK, Liu C, Haritos VS, et al. Understanding the interplay between self-assembling peptides and solution ions for tunable protein nanoparticle formation. ACS Nano, 2018, 12: 6956-6967

27 Sun F, Zhang WB, Mahdavi A, et al. Synthesis of bioactive protein hydrogels by genetically encoded SpyTag-SpyCatcher chemistry. Proc Natl Acad Sci USA, 2014, 111: 11269-11274

28 Leng Y, Wei HP, Zhang ZP, et al. Integration of a fluorescent molecular biosensor into self-assembled protein nanowires: a large sensitivity enhancement. Angew Chem Int Ed, 2010, 49: $7243-$ 7246

29 Ryadnov MG, Woolfson DN. Engineering the morphology of a self-assembling protein fibre. Nat Mater, 2003, 2: 329-332

30 Sun H, Luo Q, Hou C, et al. Nanostructures based on protein selfassembly: From hierarchical construction to bioinspired materials. Nano Today, 2017, 14: 16-41

31 Zhang X, Chu X, Wang L, et al. Rational design of a tetrameric protein to enhance interactions between self-assembled fibers gives molecular hydrogels. Angew Chem Int Ed, 2012, 51: 4388-4392

32 Garzoni M, Okuro K, Ishii N, et al. Structure and shape effects of molecular glue on supramolecular tubulin assemblies. ACS Nano, 2014, 8: 904-914

33 Yanagisawa Y, Nan Y, Okuro K, et al. Mechanically robust, readily repairable polymers via tailored noncovalent cross-linking. Science, 2018, 359: 72-76

34 Arisaka A, Mogaki R, Okuro K, et al. Caged molecular glues as photoactivatable tags for nuclear translocation of guests in living cells. J Am Chem Soc, 2018, 140: 2687-2692

35 Okuro K, Kinbara K, Tsumoto K, et al. Molecular glues carrying multiple guanidinium ion pendants via an oligoether spacer: stabilization of microtubules against depolymerization. J Am Chem Soc, 2009, 131: 1626-1627

36 Wang F, Zhu Y, Zhou L, et al. Fluorescent in situ targeting probes for rapid imaging of ovarian-cancer-specific $\gamma$-glutamyltranspeptidase. Angew Chem Int Ed, 2015, 54: 7349-7353

37 Urano Y, Sakabe M, Kosaka N, et al. Rapid cancer detection by topically spraying a $\gamma$-glutamyltranspeptidase-activated fluorescent probe. Sci Translational Med, 2011, 3: 110ra119

38 Feng Z, Wang H, Xu B. Instructed assembly of peptides for intracellular enzyme sequestration. J Am Chem Soc, 2018, 140: 16433-16437

39 Li J, Bullara D, Du X, et al. Kinetic analysis of nanostructures formed by enzyme-instructed intracellular assemblies against cancer cells. ACS Nano, 2018, 12: 3804-3815

40 Tanaka A, Fukuoka Y, Morimoto Y, et al. Cancer cell death induced by the intracellular self-assembly of an enzyme-responsive supramolecular gelator. J Am Chem Soc, 2015, 137: 770-775

41 Sweetlove LJ, Fernie AR. The role of dynamic enzyme assemblies and substrate channelling in metabolic regulation. Nat Commun, 2018, 9: 2136

Acknowledgements This work was supported by the National Science Fund for Distinguished Young Scholars (31825012), the National Key Research and Development Program of China (2017YFC1103502), the National Natural Science Foundation of China (NSFC, 51773097, 51873156 and 21876116), Tianjin Science Fund for Distinguished Young Scholars (17JCJQJC44900), the National Program for Support of Topnotch Young Professionals, the Fundamental Research Funds for the Central Universities, and the Young Elite Scientists Sponsorship Program by Tianjin (TJSQNTJ-2017-16).

Author contributions Yang Z, Wang Q and Gao J designed the project and wrote the manuscript. Shang $\mathrm{Y}$ and Wang $\mathrm{Z}$ did the synthesis and the tests of TEM, CD, Rheology and MST. Liao Y performed enzyme activity tests. Ye Z and Xiao L did TIRFM. All authors helped with data analysis and manuscript preparation.

Conflict of interest The authors declare no conflict of interest 
Supplementary information online version of the paper.

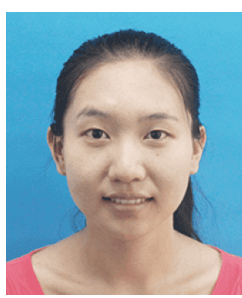

Yuna Shang received her BSc from Hebei University in 2016. Then she continued her study as a PhD candidate in Prof. Zhimou Yang's Lab in Nankai University. Her research interest mainly focuses on the growth factors mimic peptides and biohybrid hydrogels based on proteins and peptides.

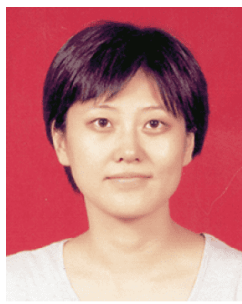

Jie Gao obtained a BSc degree in materials science and engineering from Tianjin University in 2008 , and a $\mathrm{PhD}$ degree in polymeric chemistry and physics from Nankai University in 2013. Then she joined the Faculty of Nankai University in 2013, and now she is an associate professor of biomaterials. Her research interest focuses on the development of novel supramolecular hydrogels for biomedical applications.

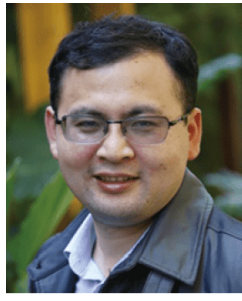

Qigang Wang received his BSc and MSc from the East China University of Science and Technology in 1999 and 2002, respectively. He obtained his $\mathrm{PhD}$ degree in 2005 from Shanghai Institute of Ceramics, CAS under the supervision of Prof. Qiuming Gao. Before starting his independent research at Tongji University in March 2011, he was a postdoctoral fellow with Prof. Takuzo Aida at Tokyo University and Prof. Bing $\mathrm{Xu}$ at Hong Kong University of Science and Technology. His research interests focus on the mild bio-oxidative preparation and biomedical application of enzymeladen hybrid hydrogel.

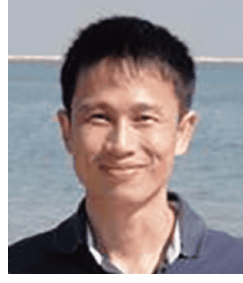

Zhimou Yang received his BSc from Nanjing University in 2001. He obtained his $\mathrm{PhD}$ degree in 2006 from Hong Kong University of Science and Technology under the supervision of Prof. Bing Xu. Before starting his independent research at Nankai University in March 2009, he was a postdoctoral fellow with Prof. Matthew Bogyo at Stanford Medical School. His research interests focus on molecular hydrogels of therapeutic agents (especially anti-cancer drugs) and short peptides and hydrogels based on protein-peptide interactions.

\section{超分子蛋白胶水及其在增强酶活性中的应用}

商宇娜 ${ }^{1}$, 廖悦 ${ }^{2}$, 叶中菊 ${ }^{3}$, 王忠彦 ${ }^{1}$, 肖乐辉 ${ }^{3}$, 高洁 ${ }^{1^{*}}$, 王启刚 ${ }^{2^{*}}$, 杨志谋 ${ }^{1 *}$

摘要 蛋白质具有许多生物学功能. 然而, 它们很容易降解和聚集, 从而失去其生物活性. 因此, 开发一种能够与蛋白质存在相互作用 力的纳米材料对蛋白质的储存和递送是十分重要的. 在本研究中, 我们偶然发现了一个新奇的多肽超分子蛋白胶 $\left(\mathrm{Nap}-\mathrm{GFFYK}(\gamma \mathrm{E})_{2^{-}}\right.$ $\mathrm{NH}_{2}$, 化合物 $\mathbf{1}$ ), 可以与蛋白质共组装形成纳米纤维和水凝胶. 我们 发现, 当化合物 $\mathbf{1}$ 接触到蛋白时会快速折叠形成 $\beta$-折叠构象, 但与聚 合物接触时未有这一现象. 全内反射苂光显微镜(TIRFM)图像清楚 地显示了蛋白质和多肽通过共组装形成纳米纤维的过程. 我们还 发现超分子蛋白胶改善了酶(脂肪酶和溶菌酶)的溶解性和分散性, 因此提高了它们(特别是在高温下)的催化活性. 更重要的是, 我们 的超分子蛋白胶可以与两种酶(GOx/HRP或GOx/cyt c) 共组装形成 纳米纤维, 显著增强串联酶促反应的催化活性. 超分子蛋白胶在蛋 白质储存、传递和生物活性调控方面具有巨大潜力. 